\title{
Constructional sustainability impact on the comfort of living environment
}

\author{
Andrey Sorokin ${ }^{1, *}$, Yulia Larionova ${ }^{2}$ and Elena Tolstykh $^{2}$ \\ ${ }^{1}$ Moscow Aviation Institute, Volokolamskoe highway, 4, Moscow, 125993, Russia \\ ${ }^{2}$ Moscow State University of Civil Engineering, Yaroslavskoe sh., 26, Moscow, 129337, Russia
}

\begin{abstract}
Modern construction is accompanied by the active appearance of various technical, technological and other solutions. In pursuit of efficiency growth, various required parameters do not always correspond with the sustainability standards of the construction unit and in prospect cause a large negative effect for real estate users. The paper exposes an analysis of urban planning solutions from the point of comfort of the living environment, as well as a proposal on the methodology for calculating the complex indicator of a comfortable living environment. In addition, the modern scientific data on ecology is analyzed, a particular attention is paid to environmental monitoring in construction. The comfort indicators of the urban environment are structured in order to determine actual trends and needs for the optimal development of urban complexes.
\end{abstract}

\section{Introduction}

The current stage of urban development is characterized by continued urbanization, the expansion of urban boundaries, large-scale renovation and reconstruction, as well as the optimization of existing urban area. Due to the lack of vacant areas for construction in such metropolises as Moscow, the renovation issue regarding industrial areas and their redevelopment has already become especially acute, and today these areas are almost the only territory for the new construction.

In addition, industrial areas with blank concrete fences, cyclone fences and fences made of metal pipes adversely affect the perception of the city's historical development. Undoubtedly, the visual environment has an impact on the mental and physiological condition of a person. The city authorities have already realized the benefits for the economy and for the appearance of the capital long ago, obtained from the reorganization and the search for new solutions for the rust belt of Moscow, which is represented by abandoned industrial areas, dormant plants and decadent harmful industries. Also redevelopment of industrial zones will affect the urban ecology, the medical and environmental components and the video ecology of urban space [1]. Nowadays, the renovation of industrial areas is not as intensive, as the renovation of residential housing units, which is carrying out according to the state program, but even the industrial territory, zone after zone, acquire a new look and a completely new functionality. The decision of the state to remove industrial objects outside the city has given a new twist to the life of the

*Corresponding author: tolstykh.elena@mail.ru 
capital, and this will allow to get rid of depressive areas in the city center and will expand opportunities for optimizing the urban environment. Up to date, the renovation issue of industrial areas is being solved gradually, but quite effectively.

\section{Materials and Methods}

The legacy of the industrial revolution after the works on adaptation of the infrastructure and land reclamation is replaced by modern residential buildings, recreational facilities and comfortable parks that improve the ecological situation in the city. However, in spite of sufficiently effective solutions for redevelopment of industrial areas, the useful potential of these facilities is not completely unlocked [2]. Residential blocks which are replacing the abandoned territories offer comfortable areas for living in the existing urban infrastructure that meets the requirements of urban planning policy of the city and the priority project «Creating a comfortable urban environment», but not designed for spontaneous growth of multi-storey residential development. The priority project "Creating a comfortable urban environment", unfortunately, is reduced to the improvement of public spaces, the promotion of best practices regarding provision of public amenities, the development of the so-called "quality index of the urban environment," and it does not take into account all spheres of life.

Constructional ecology holds the status of the applied ecology branch, as well as a subsystem of engineering ecology [3]. The sustainability of the construction is based on the information obtained from applied and general ecology, construction science, physics, chemistry, medicine, engineering geology, socio-economic, etc. Mandatory examination of projects during their implementation is carried out for all the sections presented, which are designed for the initial exploitation period of units. The figures obtained meet all the environmental protection requirements and change both for the better and for the worse over the exploitation period. In order to ensure stability of environmental protection indicators, it is necessary to conduct an environmental monitoring, which allows to develop and organize a system of observations, assessment and prediction of the environmental condition that will help to maintain the environment in a satisfactory condition [4].

Thus, it is now generally accepted that the strategy of sustainable development determines the need for developing environmental knowledge and consciousness, the formation of an ecological culture, including a system of skills, knowledge and environmentally justifiable behavior in professional activity [5]. This is especially relevant for construction problems, since construction is considered to be the foundation of the economy as a whole. The sustainable development of the whole society will depend on its coexistence with the natural environment. As a science, constructional sustainability promotes the formation of new thinking of the builders, ecological consciousness in the modern developing world.

As it is known, the construction includes both the execution of construction works and manufacturing processes for the production of building products and materials, the extraction of natural building materials and raw materials. Thus, there is an all-round impact on the biosphere (alienation of large areas, the formation of a significant amount of waste, etc.).

\section{Results}

Constructional sustainability is an interdisciplinary science dealing with environmental problems, which is aimed at understanding the complete society - environment system and its preservation [6]. The main problems of the constructional sustainability are related to the 
need for solving a number of interrelated problems on environmental management and protection (7). It is important to identify the following group of problems:

1. Environmental standardization. The substantiated engineering and environmental standardization should include the calculation of optimal tolerances for the environment from the point of view of industrial and construction processes. It also should contain a complex of reasonable measures for the environmental protection of natural objects within the boundaries of the designed natural and technical system and in the construction site.

2. Rational use of the main and related mineral products. Among them there are rocks that contain or overlap the mineral products, groundwater, etc.

3. Rational land use and land preservation, conservation of the land surface and natural relief. For example, in an urban environment the landscape design should be used. It is necessary to look for ways of using the geological environment as a space for communication laying, underground construction, production placement.

4. Preventing the contamination of geological objects as well as groundwater contained in them while creating different surface storages, deep depletions, creation of landfills for disposal of industrial wastes and wastewater treatment systems.

5. Preservation of the foundations stability and the stability of their bases regarding buildings during construction and exploitation periods of public, industrial and residential complexes. It is necessary due to the changes in the bearing capacity of soils that lie at the base of such structures or to the development of harmful geological technogenic processes.

6. Regulation of moisture and energy balance of mineral material between the environment and the atmosphere, which meets the optimal conditions for the existence and development of different-scale ecological systems.

7. Preservation or restoration of natural objects of a particular scientific, historical or aesthetic value (natural landmarks and cultural heritage, reserves, etc.).

8. Environmental impact assessment: retrospective, operational, prospective. The system of environmental impact assessment should be organized according to the same principles as the rationing arrangements (by objects, territories, current, prospective).

9. Consistent process of anthropogenic change of the natural-technical system within the boundaries of a specific construction area determines the objective problem with restoring the lost properties of natural landscapes in accordance with the nature of the changes that have occurred.

10. The use of environmentally friendly construction technologies, construction machinery and mechanisms that have minimal physical impact (vibration, noise, electromagnetic fields, light) on the environment is also a problem.

11. Utilization of industrial and constructional waste in order to produce cheap building materials is also significant.

12. Studying and applying modern achievements in the field of renewable energy sources and preserving non-renewable energy sources.

13. Environmental safety of public and residential buildings. The essence of this problem is to ensure the comfort of living and human activity in rated conditions, and do not affect health and the ecosystem condition negatively.

14. Raising the environmental safety level of building materials.

15. Integrating modern monitoring methods for the environment in order to make relevant decisions on changes in the design, construction process and building exploitation. 


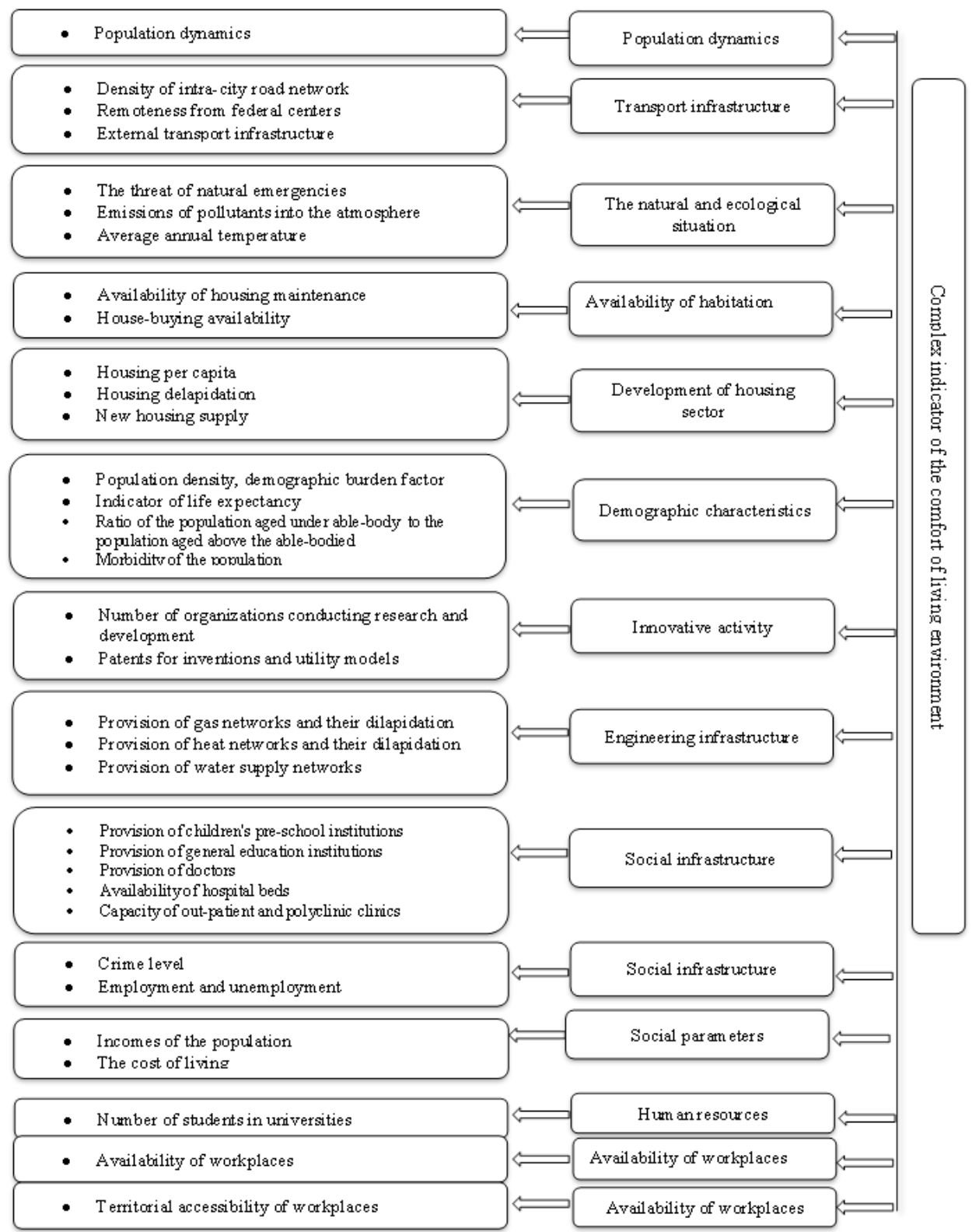

Fig. 1. Comfort indicators of the urban environment.

According to the assessment methodology of the urban living environment quality, approved by the order of the Regional Development Ministry of the Russian Federation, 13 basic enlarged indices can be distinguished. Those are population dynamics, demographic characteristics of the population, social parameters of society, welfare of citizens, social infrastructure, economy of the cities, housing sector development, housing availability, innovative activity, transport infrastructure, utility infrastructure, human resources, natural and environmental situation. These indices characterize the quality of the urban living environment. In turn, each index is characterized by a set of indicators. The reduced indicators of the comfort of the urban environment are relevant, but do not completely represent the necessary conditions for the residents. Due to the increasing unemployment 
level, as well as the expanding borders of Moscow, the issue of workplace accessibility and availability has become acute, but has not received a worthy reflection in renovation projects. Most residents of bedroom districts and areas with a high construction density spend 1.5 hours to get to work in average, and the number of unemployed working-age population is $1.3 \%$, while in Moscow this figure is the lowest in the country. This state of affairs forces to take this problem into account as a stimulus for allocating two more important indices that provide a comfortable living environment: the availability of workplaces and their territorial accessibility. To provide Moscow residents with jobs, while observing a relative balance of concentration of workplaces, it is proposed to take a fresh look at the issue of renovation of industrial territories [8]. Industrial zones have the potential to be transformed into comfortable multifunctional complexes with comfortable housing, developed infrastructure and a sufficient number of workplaces that are within walking distance, capable of providing employment for at least $50 \%$ of the citizens living in the complex. Workplaces in these multifunctional complexes can provide both infrastructure facilities (hospitals, schools, kindergartens, shops, fast food spots, manufacture facilities) and multi-storey office buildings with affordable rental for various activities. However, the indicators of accessibility and availability of workplaces are not relative and their effect on a complex index of the living environment quality can be estimated considering the percentage of employees among people residing in multifunctional complexes [9].

\section{Discussion}

This renovation solution will allow to remove the load from the capital traffic that does not cope with constant labor migration on weekdays. The renovation of five-storey buildings in Moscow is being carried out quite effectively, multi-storey residential buildings are replacing five-storey buildings, which causes the load on city transport junctions to increase several times. That occurs due to the fact that the standards for providing residents with social and cultural objects are taken into account during the renovation, but transport load is not. According to that, the most correct organizational decision will be the erection of multifunctional complexes replacing such cumbersome industrial territories, as well as the inclusion of comfort indicators of the urban environment, such as the availability of workplaces and their accessibility, meeting the requirements of a modern metropolitan resident and allowing more efficient and comprehensive solution of the problem in order to create a comfortable living environment $[10,11]$. Motor and pedestrian traffic play an important role in the life of each city, and the most valuable and limited resource for citizens is time, which everyone spends for commuting. It is often that citizens living at one end of Moscow are forced to commute to a workplace located at the other end of the city, which creates an additional stress factor for people forced to spend a lot of time in traffic jams. In addition, public transport is often the nidus of viral diseases, therefore, the availability of a workplace located in walking distance will allow to avoid unnecessary everyday presence in crowded places, which will affect the sickness rate and therefore the demographic characteristics index of the population $[12,13]$.

Lest we forget about some categories of unemployed citizens, which will be affected by such a design solution for the renovation of industrial zones. Those are such categories as people of retirement age and young mothers. Close location of the workplace will expand the category of able to work citizens, and will allow them to work comfortably, since people of retirement age, as well as young mothers sometimes cannot work because of the territorial remoteness of vacancies. This situation is contrary to the social orientation. A lot of people will be able to work across the road. This fact will affect the index of social parameters. The remoteness of workplaces from the residential places also greatly increases 
the social stratification due to the long time spent on the road and a division of the social circle of people's communication into colleagues and neighbors [14].

\section{Conclusion}

Changes in the ecological environment as a result of construction affect the entire biosystem over time, including people. Based on the above, we leap to the conclusion that it is necessary to take into account the opinion of ecologists more during the construction, as it helps to prevent an ecological catastrophe. Using the corresponding approaches wil allow to minimize the harm to humanity.

Summarizing the above, one can conclude as follows: the construction of multifunctional complexes which will replace industrial areas is a fairly effective solution affecting the city's economy and social component. In addition, the calculation of the comfort complex indicator of the living environment taking into account the indices of workplace availability completely represents the satisfaction of residents with the urban environment.

\section{References}

1. S.M.R. Alavipour, D. Arditi, Journal of Construction Engineering and Management 144(4), 04018012 (2018)

2. A.K. Orlov, MATEC Web of Conferences 106, 08013 (2017)

3. A. Larionov, E. Nezhnikova, International Journal of Applied Engineering Research 6, 4433-4439 (2016)

4. E. Nezhnikova, IOP Conf. Series: Earth and Environmental Science 90, 012161 (2017) doi:10.1088/1755-1315/90/1/012161

5. V.P. Generalov, E.M. Generalova, Vestnik Orenburgskogo gosudarstvennogo universiteta 5(180), 128-131 (2015)

6. V. Kankhva, IOP Conf. Series: Earth and Environmental Science 90, 012175 (2017) doi:10.1088/1755-1315/90/1/012175

7. R. Golov, V. Shilov, S. Silantiev, ASEE International Forum, Columbus 20766 (2017)

8. N. Safronova, E. Nezhnikova, A. Kolhidov, MATEC Web of Conferences (2017) doi:10.1051/matecconf/201710608024

9. P. Petronijević, N. Ivanišević, M. Rakočević, D. Arizanović, Journal of Applied Engineering Science 10 (2012) doi:10.5937/jaes10-1664

10. M. Lazarevska, M. Knežević, M. Cvetkovska, N. Ivanišević, T. Samardžioska, A. Trombeva-Gavriloska, Gradjevinar 7/2017, 64 (2012) ISSN (on line): 1333-9095, ISSN (printed) 0350-2465

11. D. Silka, V. Kankhva, MATEC Web of Conferences 106, 08031 (2017) doi: 10.1051/matecconf/201710608031

12. B. Alexander, B. Vladislav, Journal of Physical Education and Sport 15, 362-364 (2015), doi:10.7752/jpes.2015.03054

13. O.M. Khudolii, O.V. Ivashchenko, S.S. Iermakov, O.G. Rumba, Science of Gymnastics Journal 8, 215-228 (2016)

14. B. Alexander, Journal of Physical Education and Sport 15, 417-425 (2015), doi:10.7752/jpes.2015.03062 